\title{
«НОВЫЙ ИСТОРИЗМ» И ПОСТМОДЕРНИСТСКАЯ КОНЦЕПЦИЯ РУДОЛЬФА АНКЕРСМИТА
}

\author{
Ю.А. Мартынова, Д.Е. Мартыноов \\ Казанский (Приволжский) федеральный университет, г. Казань, 420008, Россия
}

\begin{abstract}
Аннотация
В статье осуществляется рефлексия современной историографической ситуации, в которой всеохватные исторические теории воспринимаются как препятствие для узкоспециальных конкретных исследований. Отмечается, что в философском плане на первое место вышли структурализм и философия языка, которые привели к почти безраздельному господству герменевтического подхода в культуре - возобладал текстоцентризм. Нидерландский философ Рудольф Анкерсмит утверждал, что постмодернизм является теорией истории и одновременно «теорией об истории». Историзм, по Р. Анкерсмиту, есть теория идей. Превращение исторических форм происходит в условиях, когда стирается различие между текстом и реальностью (репрезентируемой в тексте), причем реальность оказывается «лишней» в условиях перепроизводства смыслов и интерпретаций. Репрезентация тем самым становится на место реальности. Движение «нового историзма» возникло в США во второй половине 80-х годов XX в. как ответ литературоведения на «вызовы» культурного материализма, феминизма или социальной истории. Исторический контекст рассматривается представителями проекта «новой историографии» как система культуры, то есть социальные институты и практики (включая политические) истолковываются как функции этой системы, а не наоборот.
\end{abstract}

Ключевые слова: историзм, «Новый историзм», постмодерн, историческая критика, метанарратив, Р. Анкерсмит, С. Гринблат, Г. Визер

Ситуация постмодерна возникла в условиях радикального сомнения в возможности философии быть основой мировоззренческого и нарративного единства. Все великие французские постмодернисты декларировали отказ (не всегда последовательный) от попыток систематизации и представления мира в виде жестких, самозамкнутых систем. Постмодернисты, начиная с М. Фуко, много писали о недоверии к логическим формам, словам, в которых прозревали дискурс власти и аппарат насилия, и стремились преодолеть рациональную однозначность и предсказуемость [1, с. 145-147]. Один из соавторов данной статьи в свое время участвовал в дискуссии о применимости постмодернистских подходов к историческому процессу как таковому (участники пришли к отрицательным выводам), что и послужило первичным толчком к написанию статьи. Равным образом авторы осознают разницу между постмодернистскими историческими практиками и собственно постмодернистскими концепциями истории, которые тесно сопряжены со структурализмом и постструктурализмом. Соответственно, 
любой систематический подход истолковывается представителями структурализма как миф или метафора [2, с. 269-321]. Оперируя понятием «историзм», мы стремились держаться в русле определения А.М. Руткевича [3].

Знаменитый нидерландский исследователь интеллектуальной истории Франклин Рудольф Анкерсмит ${ }^{1}$ посвятил историзму в ситуации постмодернизма отдельную работу (Анк1). Сама по себе ситуация уже вписана в большой контекст, среди созидателей которого можно назвать в первую очередь Поля Рикёра (19132005). Приняв структурализм как науку, П. Рикёр в своей известной работе «Конфликт интерпретаций» начал формулировать методологию исследования явлений культуры и человека как ее субъекта. Собственно, в 80-е годы XX в. П. Рикёр приступил к осмыслению повествовательной функции культуры, для чего считал необходимым объединение феноменологии с лингвистическим анализом, а герменевтики - с аналитической философией. Целью его было бытие культуры как исторической целостности [4, с. 33-34]. Однако заметим, что для целей данного конкретного исследования не требуется столь высокий уровень обобщений, которым отличаются труды П. Рикёра.

Согласно Р. Анкерсмиту, постмодернизм является теорией истории и одновременно «теорией об истории». Последнее отражено в классической работе Ж.Ф. Лиотара «Ситуация постмодерна»: постмодерн отказывается от метанарратива, от формализации научного знания, зародившейся в эпоху Просвещения и обусловившей в качестве первичной функции метанарратива легитимизацию самой науки. Ж.Ф. Лиотар выделял три важнейших примера метанарратива. Во-первых, это просвещенческая утопия либерализирующих результатов прогресса научного знания, во-вторых, это рассказ о том, как прогресс способствует моральному и духовному формированию нации, в-третьих, это марксизм. Проблема заключается в том, что названные метанарративы сами распались вслед за тем, как произошла изоляция языков различных научных сообществ, образующих современный интеллектуальный мир (Анк1, с. 308-310). По мнению Р. Анкерсмита, наиболее эффективной интеллектуальной критикой метанарратива является историзм, который, несмотря на «квази-позитивистскую» маскировку, остается главным источником современного исторического сознания. Отличительным признаком истористской исторической мысли является отрицание спекулятивных исторических систем, наподобие гегелевской (Анк1, с. 311-312).

Историзм, по Р. Анкерсмиту, есть теория «исторических форм», иначе говоря, морфология культуры имеет прямое отношение к историзму. Идеи либо формы воплощали особую индивидуальность исторических эпох или феноменов.

\footnotetext{
${ }^{1}$ Franklin Rudolf Ankersmit (род. 1945) - нидерландский теоретик интеллектуальной истории. Начинал изучать математику и физику в Лейденском университете, в 1981 г. защитил в Университете Гронингена докторскую диссертацию «Нарративная логика: семантический анализ языка историка». С 1986 г. состоит в Королевской нидерландской Академии искусств и наук, с 2011 г. - член Европейской академии, до 2017 г. возглавлял «Журнал философии истории». В 1992-2010 гг. - профессор интеллектуальной истории и философии истории Университета Гронингена. Автор 15 монографий и более 250 статей. Награжден орденом Оранских-Нассау (2010). В своей философии истории принципиально основывался на эпистемологии Г.В. Лейбница как единственного европейского мыслителя, поставившего в центр репрезентацию. Резкий противник неолиберализма, охарактеризовал его идеологию как «возвращение к средневековому феодализму»; равным образом критикует представительную демократию, характеризуя ее как смесь «аристократии, выборных институтов трех сословий и концепции суверенитета, унаследованной от абсолютизма» (перевод наш. - Д.М., Ю.М.). См.: Uittocht bij Forum voor Democratie houdt aan [нидерл.] // DPG Media B.V. 2018. 9 febr. URL: https://www.parool.n1/nieuws/uittocht-bij-forum-voor-democratie-houdt-aan bb252176/?ref.
} 
Соответственно, в системе представлений историзма идеи/формы могут быть познаны только в их различии. Историзм исходит из того, что сами по себе формы истории определяются отличиями друг от друга, а не соотнесением с некоторым общим содержанием. Эта ситуация накладывалась на убеждение, что всё существующее есть результат исторической эволюции, а сущность наций, институтов или даже конкретных людей может быть найдена в их прошлом (Анк1, с. 312-313). М. Мандельбаум ${ }^{2}$ уточнял, что с позиции историзма определенную роль в понимании процесса развития играет также аксиологический аспект, потому что от него зависит адекватное понимание природы того или иного явления и его ценности $[5$, p. 42]. Это обрекает носителя исторического сознания не просто на определение исторических форм или вычленение идей (например, идеи нации), но и определение их различия на ранней или поздней стадии существования. Априори предполагается, что исторические формы или идеи непосредственно характеризуют историческую действительность. Здесь происходит сопряжение с позитивистским историзмом, в частности в версии Л. фон Ранке [6]. Проблема же заключается в том, что для каждого исторического явления или периода существует большое и постоянно увеличивающееся число конкурирующих интерпретаций. Соответственно, идеи, облеченные в те или иные формы, есть часть исторической реальности в себе самой, и невозможно ответить, какая именно интерпретация есть «правильное» воспроизведение исторических идей. «Говоря провокационно, чем более высококачественные интерпретации мы имеем, тем более скомпрометированным становится идеал "правильной" интерпретации» (Анк1, с. 314). Результат таков: стирается различие между историческим текстом и исторической реальностью.

Ситуацию постмодерна Р. Анкерсмит связывал также с перепроизводством смыслов и текстов, в которых происходит «растворение» реальности. С историзмом постмодерн роднит, согласно его мысли, опора на логику различия, но уже в деконструкции различия между миром и описывающим его структуры языком. Более того, можно утверждать, что тезис «ничего не существует вне текста» есть просто современный эквивалент идеализма двухсотлетней давности, что историзм обладает «врожденным талантом» для трансформации в постмодернизм (Анк1, с. 316). Разница между ними заключается в том, что в постмодернизме осуществляется взгляд на историю с позиции языка.

В рассуждениях Р. Анкерсмита заметную роль играет историческая репрезентация. В переводе на язык постмодерна главный вопрос современного историзма - отношения между реальностью и ее репрезентацией в историческом тексте. Ответ здесь будет следующим: репрезентация имеет тенденцию стать не менее реальной, чем репрезентируемое, а непосредственная реальность имеет тенденцию превратиться в нечто избыточное (Анк1, с. 317-318). Более того: уже нельзя говорить об историописании вообще. Использование термина «репрезентация» предполагает наличие независимой от познающего субъекта реальности, которая затем репрезентируется благодаря историописанию. Согласно

\footnotetext{
${ }^{2}$ Maurice Mandelbaum (1908-1987) - американский философ. С 1957 г. до самой кончины преподавал в Дартмутском колледже. Известен своими работами в области феноменологии, эпистемологии и истории идей. См.: Beck L.W., Bowie N.E., Duggan T. Maurice H. Mandelbaum, 1908-1987 // Proc. Address. Am. Philos. Assoc. 1987. V. 60, No 5. P. 858-861.
} 
Р. Анкерсмиту, постмодернизм следует воспринимать как самосознание модернизма и новую теорию репрезентации (Анк1, с. 322). Однако в русле перфомансивного постмодернистского сознания репрезентация подменяется презентацией. Происходит это отчасти потому, что в сфере искусства и эстетики проблема адекватности репрезентации мало актуальна или, по крайней мере, менее актуальна, чем в исторической реальности. Известный исследователь левой направленности Фредрик Джеймисон отметил, что если стирается различие между реальностью и репрезентацией, то исчезает и глубина (depthlessness) [7, p. 58]. Р. Анкерсмит в этой связи заметил, что оппозиция языка и реальности приводит к дублированию и в языке, и в реальности, что требует адекватности репрезентации. В свою очередь, при оценке репрезентации с позиции адекватности получается, что иерархия репрезентаций должна иметь свою копию в репрезентируемой реальности. Это и производит глубину: признавая различие языка и реальности, мы автоматически переносим реальность на передний план (она есть существенное), а прочие проявления реальности образуют задний план (Анк1, с. 323).

Понятие глубины имеет особое значение для эстетики постмодернизма и понимания современного искусства. Искусство модернизма не доверяло реализму и натурализму и отвергало их именно с позиции невозможности создать адекватную связь между репрезентируемым и репрезентацией. Для кубиста, фовиста или - тем более! - супрематиста сущность реальности находится не там, где ее пытается отыскать живописец-реалист. Постмодернизм вообще не интересуется зазором между репрезентируемым и репрезентацией, поскольку не признает никакой структуры в хаосе бытия. «Постмодернизм функционирует в пределах матрицы деталей» (Анк1, с. 324).

Вслед за М. Кукарцевой рассмотрим сходства и различия историзма и постмодернизма у Р. Анкерсмита ${ }^{3}$. Нидерландский исследователь диалектически считает историзм переходом к постмодернизму, называя последний радикальным историзмом. Основные сходства и различия представлены в табл. 1.

В то время как Р. Анкерсмит принципиально позиционировал и позиционирует себя в качестве представителя респектабельных академических кругов (и так же воспринимает постмодерн, не выводя его за пределы университетской среды), в США параллельно происходило разворачивание нового проекта. Речь идет о «новом истори(ци)зме», начатом литературоведами - исследователями английской литературы. Цели нового проекта изначально лежали на стыке собственно академических дисциплин и политики как попытка восстановить историческое измерение в американском литературоведении $[8, \text { p. 293] }]^{4}$. Луис Монтроз определял новый историзм как «социокультурное поле», в котором можно было бы осуществлять работу в сопряжении с современными недискурсивными практиками. В известном смысле это противопоставлялось современным «ортодоксальным» школам: культурному материализму, феминизму или социальной истории. В методологическом плане Л. Монтроз хотел отойти от интертекстуальности,

\footnotetext{
${ }^{3}$ Кукарцева М.Ф. Анкерсмит и «новая» философия истории // Анкерсмит Ф. История и тропология: взлет и падение метафоры. М.: Прогресс-Традиция, 2003. С. 51-54. (Данная редакция перевода изобилует ошибками и не использовалась нами. - Ю.М., Д.М.).

${ }^{4}$ Цитируется «Комментарий» Х. Уайта.
} 
Сходства и различия историзма и постмодернизма по Р. Анкерсмиту

\begin{tabular}{|c|c|}
\hline Сходства & Различия \\
\hline $\begin{array}{l}\text { Отрицание спекулятивных систем } \\
\text { философии истории (по Дж. Вико, } \\
\text { Г. Гегелю, К. Марксу, О. Шпенглеру, } \\
\text { А. Тойнби), то есть метанарратива }\end{array}$ & $\begin{array}{l}\text { Отношение к контексту. Историзм } \\
\text { конструирует контекст исторических } \\
\text { событий, а постмодернизм деконстру- } \\
\text { ирует его }\end{array}$ \\
\hline $\begin{array}{l}\text { Различие как базовая категория. Исто- } \\
\text { ризм убежден в том, что понимание } \\
\text { исторических эпох, форм и идей воз- } \\
\text { можно только на основе их отличия } \\
\text { друг от друга. Тем самым история раз- } \\
\text { бивается на множество отдельных ис- } \\
\text { торий. Постмодернизм умножает исто- } \\
\text { рические интерпретации, что в резуль- } \\
\text { тате приводит к тому же самому. Исто- } \\
\text { ризм и постмодернизм равно пробле- } \\
\text { матизируют объективную историче- } \\
\text { скую реальность. Но если в историзме } \\
\text { рассмотрение исторического мира в } \\
\text { терминах языка являлось только тен- } \\
\text { денцией, то в постмодернизме - это от- } \\
\text { правная точка исследований }\end{array}$ & $\begin{array}{l}\text { Отношение к историческим свиде- } \\
\text { тельствам (исторической реальности). } \\
\text { Историцисты изучают свидетельства } \\
\text { как фрагменты автономной историче- } \\
\text { ской реальности, и это сообщает им } \\
\text { определенные сведения о прошлом. } \\
\text { У постмодернистов репрезентация вос- } \\
\text { принимается не менее реальной, чем } \\
\text { сама реальность, в результате чего по- } \\
\text { следняя становится просто избыточной } \\
\text { по сравнению со своей репрезентацией. } \\
\text { Ж. Бодрийяр назвал этот феномен ги- } \\
\text { перреальностью. Результат - фрагмен- } \\
\text { тирование и отсутствие чувства един- } \\
\text { ства прошлого }\end{array}$ \\
\hline $\begin{array}{l}\text { Схожесть теории репрезентации. Ее } \\
\text { основными чертами можно считать } \\
\text { фрагментаризацию изображаемого и } \\
\text { отрицание единства прошлого. В пост- } \\
\text { модернизме фрагментаризация силь- } \\
\text { нее. В историзме указанный элемент } \\
\text { выражен слабее }\end{array}$ & $\begin{array}{l}\text { Отношение к историческому опыту. } \\
\text { Историцистский опыт прошлого стре- } \\
\text { мится к возрождению прошлого, по- } \\
\text { гружению в него, к получению опыт- } \\
\text { ных знаний, которые принадлежат } \\
\text { прошлому непосредственно. В резуль- } \\
\text { тате достигается обратный результат, } \\
\text { ибо опыт прошлого подменяется про- } \\
\text { шлым опытом, что не одно и то же. } \\
\text { Постмодернистский анализ феномена } \\
\text { исторического опыта построен совсем } \\
\text { на других основаниях }\end{array}$ \\
\hline
\end{tabular}

одновременно заменив диахронию автономно существующей истории литературы синхронным текстом культуры как системы. Хейден Уайт в этой связи отметил, что здесь сразу произошло фундаментальное замещение: культурная система вместо «социальных систем современности и недискурсивных практик» (цит. по [8, p. 293]). Кроме того, Л. Монтроз имплицитно стремился отойти от восприятия литературы как корпуса текстов в постструктуралистском смысле этого слова (единство языка, дискурса и порождающей культуры) [8, p. 293]. Таким образом, согласно Х. Уайту, представители нового историзма отказываются от формального подхода к изучению литературных текстов ради филологического подхода. Тонкость заключается в том, что исторический контекст рассматривается как система культуры, то есть социальные институты и практики

\footnotetext{
${ }^{5}$ Рассмотрению данных оснований целиком посвящена монография Р. Анкерсмита «Возвышенный исторический опыт» (Анк2).
} 
(включая политические) истолковываются как функции этой системы, а не наоборот. В известном смысле это возврат к историческому идеализму [8, p. 294].

Институционализации новой историографии предшествовало движение американской новой критики (American New Criticism), которая отмежевалась от контекстуальной интерпретации, основываясь на тезисе, что истинные смыслы риторики или авторского замысла «затенены» критиками прошлого, которые либо аффективно, либо преднамеренно искажали «путь» к оригиналу. Подобно Рудольфу Анкерсмиту в Европе Брук Томас также заявил, что деконструктивизм является вариантом историзма. Принципиальное отличие нового историзма кроется во внимании к институционному прошлому критики, которая всегда служит чьим-то культурным интересам [9, p. 130-131]. Первым представителем нового историзма считается Стивен Гринблат ${ }^{6}$, известный своими работами в области шекспироведения и английского Ренессанса. Именно он и ввел понятие «новый историзм».

В 1989 г. под редакцией Гарольда Визера ${ }^{7}$ вышла антология «Новый историзм», признанная «революционной». В предисловии были обозначены ключевые теоретические и методологические признаки, которые встречаются в трудах всех представителей движения [8, p. XI]:

1. Выразительные средства всегда встроены в сеть материальных практик.

2. Каждый акт критики использует инструменты, которые осуждаются у критикуемого.

3. Литературные и нелитературные тексты неотделимы друг от друга.

4. Ни один из дискурсов не обеспечивает доступа к вечным и неизменным истинам и не выражает истинной человеческой природы.

5. Критический метод и язык, пригодный для описания культуры в условиях капиталистических отношений, выражают экономические отношения, для описания которых они используются.

Тем не менее профессор Лондонского университета Пол Гамильтон утверждает, что С. Гринблат, по сути, свел свой метод к герменевтике в духе Мишеля Фуко и Клиффорда Гирца. С. Гринблат является одним из апологетов культурного детерминизма, который полностью унаследовал от К. Гирца. Сам К. Гирц описывал его парадоксально: в парадигме культурного материализма следует доказать, что культура является определяющим фактором материальной жизни людей и одновременно в нынешнем состоянии она не является средством абсолютного выражения человеческих возможностей [9, р. 133]. Парадокс снимается утверждением, что не следует рассматривать развитие психики и развитие культуры как параллельные отдельные друг от друга процессы, так же как и степень технологического развития не имеет прямого отношения к экзистенциальной реализации человеческой природы. Однако это же означает необходимость применения

\footnotetext{
${ }^{6}$ Stephen Jay Greenblatt (p. 1943) - американский историк литературы ашкеназского происхождения. Профессор Калифорнийского университета в Беркли (1972-2000) и Гарвардского университета (с 2000 г.), главный редактор издания "The Norton Shakespeare". Приглашенный профессор Парижского и Флорентийского университетов, стипендиат Американской академии в Риме. Лауреат многочисленных наград, включая Шекспировскую и Пулитцеровскую премии.

${ }^{7}$ Harold Aram Veeser (р. 1950) - американский культуролог армянского происхождения. Профессор Городского колледжа Нью-Йорка. Редактор-составитель двух изданий «Нового историзма» [8], в 2010 г. опубликовал исследование "Edward Said: The Charisma of Criticism”. Публикуется также в профессиональных изданиях, посвященных арменоведению.
} 
сравнительного метода ввиду невозможности изучения культуры исходя из нее самой. К. Гирц приводил в пример формулу традиционной культуры индонезийцев: «Быть человеком - означает быть яванцем» [9, p. 134].

Основываясь на тех же постулатах, С. Гринблат считает возможным сравнивать культуру шекспировского времени с современным либеральным гуманизмом. Глубинная суть его метода состоит в том, что мы сегодняшние имеем возможность вести с У. Шекспиром диалог и применять критический потенциал его драматургии для наших собственных целей, используя разницу между культурами XVII и XXI вв. При этом исключаются те элементы поведения и культурные установки, которые противоречат либеральному гуманизму, и отбираются лишь те вневременные ценности, которые коррелируют с нашим мировоззрением [9, р. 135-136]. Солидаризируясь с М. Фуко, С. Гринблат растворил историю человека в истории власти, в результате чего на первый план выходят проблемы господства, угнетения и сопротивления. По мнению же П. Гамильтона, проблема коренится в другом: мы не можем быть елизаветинцами или якобитами, так же как и яванцами. В произведениях У. Шекспира выражена конкретная историческая реальность, в которой реализовывалась человеческая природа, и в этой реальности невозможно отыскать конкретные социальные или моральные потенции, реализуемые в нашем времени. Поэтому С. Гринблат, подчеркивая социальный характер художественной реальности, вынужден искать возможность представить свой объект как элемент в цепи существования объектов во времени, что и делает возможной его оценку в нашей современности [9, p. 137].

В этом плане очень показательна оценка нового историзма Аллена Данна и Томаса Хэддокса: методология нового историзма стирает различия между старым, позитивистским историзмом и герменевтикой, которая характеризует современные формы историзма. Исследователи, практикующие новый историзм, могут отныне «не беспокоиться о том, что их работа есть не что иное, как отражение непризнанных предрассудков их собственного времени. Как правило, они ссылаются на исторические авторитеты... отвергая любые претензии на научную объективность» ${ }^{8}[10, \mathrm{p} . \mathrm{XVI}]^{9}$.

Рассмотренные построения, по нашему мнению, в очередной раз подтверждают специфику исторического знания, которое вынуждено в меняющемся мире каждый раз обеспечивать исполнение как «заказа» действующей власти, так и собственно социального заказа. Декларации разрыва с классической рациональностью, по всей видимости, остаются именно декларациями, поскольку не ведут к изменению собственно исследовательских процедур или созданию принципиально новых познавательных инструментов. Выхода из-под «идеологического диктата» так и не произошло, а последовательное применение деконструкции породило, например, «феномен Фоменко» (хотя здесь нельзя исключить возможности розыгрыша, который нежданно для своих творцов зажил собственной жизнью и даже стал приносить ощутимую материальную прибыль) $[13$, с. 5].

\footnotetext{
${ }^{8}$ Перевод наш. - Ю.М., Д.М.

${ }^{9}$ В российской историографии также представлено исследование нового историзма с институциональной точки зрения [11], также см. [12]. Обращает на себя внимание то, что представители нового историзма поставили в центр своих теоретических рассуждений концепцию Аристотеля о том, что «хорошая литература фиксирует суть вещей» [12, с. 137].
} 
Очевидно, что даже если тип рациональности (представленный en masse) и меняется, то процесс этот имеет нелинейный, дисконтинуальный характер. Гораздо более существенным является изменение культурного контекста, поскольку общепризнанным в философии истории XX в. стало признание истины результатом согласия, консолидации носителей исторического сознания - конкретных людей. Как было очевидно еще Дж. Вико, истина коммуникативна, конвенциональна и исторична, то есть контекстуальна [9, р. 30-31]. Консолидация как критерий истины размывается в силу глобализации информационного и культурного пространства, когда на смену мультикультурализму приходит транскультурализм - сознательный выбор культурной и языковой принадлежности. Релятивизация ценностей и смыслов и переход от их усвоения к производству и перепроизводству приводят к усилению антропоцентризма и - как следствие дивергентности взаимодействия коллективов и отдельных интеллектуалов, занятых осмыслением происходящих процессов.

\section{Источники}

Анк1 - Анкерсмит Ф.Р. История и тропология: взлет и падение метафоры / Пер. с англ.: М. Кукарцева, Е. Коломоец, В. Кашаева. - М.: Канон+: Реабилитация, 2009. - 400 с.

Анк2 - Анкерсмит Ф.Р. Возвышенный исторический опыт. - М.: Европа, 2007. - 612 с.

\section{Литература}

1. Калимонов И.К. Основы научных исследований (зарубежная история). - Казань: Казан. гос. ун-т, 2006. - 276 с.

2. Уэст Д. Континентальная философия. Введение. - М.: Изд. дом «Дело» РАНХиГС, 2015. - $448 \mathrm{c}$.

3. Руткевич A.M. Историзм и его критики // Вопр. философии. - 2018. - № 12. C. 24-36. - doi: 10.31857/S004287440002580-3.

4. Рикёр П. Конфликт интерпретаций: Очерки о герменевтике / Пер. с фр. И.С. Вдовиной. - М.: Акад. проект, 2008. - 695 с.

5. Mandelbaum M. History, Man, and Reason: A Study in Nineteenth-Century Thought. Baltimore; London: Johns Hopkins Univ. Press, 1971. - 553 p.

6. Вайнштейн О.Л. Леопольд фон Ранке и современная буржуазная историография // Критика новейшей буржуазной историографии: Сб. ст. - Л.: Изд. АН СССР, 1961. С. 113-149. (Труды Ленингр. отд-ния Ин-та истории. Вып. 3)

7. Jameson F. Postmodernism, or, the cultural logic of late capitalism // New Left Rev. 1984. - No 146. - P. 59-92.

8. The New Historicism / Ed. by H. Aram Veeser. - L.: Routledge, 2016. - 336 p.

9. Hamilton P. Historicism. - London; N. Y.: Routledge, 2003. - 211 p.

10. The Limits of Literary Historicism / Ed. by A. Dunn, T.F. Haddox. - Knoxville: The Univ. of Tennessee Press, 2011. - XXV, 180 p.

11. Анисимова А.Э. «Новый историзм»: Науковедческий анализ. - М.: ИНИОН РАН, 2010. - $154 \mathrm{c}$.

12. Хлебников Г.В. Рец. на кн.: 2010.03.020. Анисимова А.Э. «Новый историзм»: Науковедческий анализ / РАН ИНИОН. Центр научн.-информ. исслед. по науке, образованию и технологиям; отв. ред. Ракитов А.И. - М., 2010. - 154 с. // Социальные и 
гуманитарные науки. Отечественная и зарубежная литература. Сер. 3: Философия: Реферативный журнал. - 2010. - № 3. - С. 133-141.

13. Шмидт С.О. «Феномен Фоменко» в контексте изучения современного общественного исторического сознания. - М.: Наука, 2005. - 73 с.

Поступила в редакцию 15.03.2021

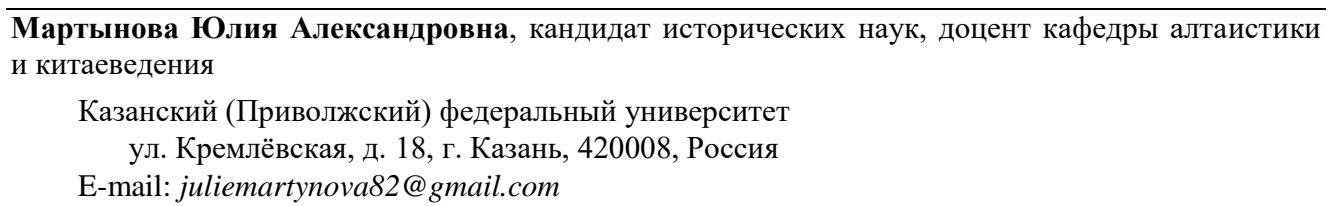

Мартынов Дмитрий Евгеньевич, доктор исторических наук, профессор кафедры алтаистики и китаеведения

Казанский (Приволжский) федеральный университет

ул. Кремлёвская, д. 18, г. Казань, 420008, Россия

E-mail: dmitrymartynov80@mail.ru

ISSN 2541-7738 (Print)

ISSN 2500-2171 (Online)

UCHENYE ZAPISKI KAZANSKOGO UNIVERSITETA. SERIYA GUMANITARNYE NAUKI

(Proceedings of Kazan University. Humanities Series)

2021, vol. 163, no. 3, pp. 21-30

ORIGINAL ARTICLE

doi: 10.26907/2541-7738.2021.3.21-30

“New Historicism" and Rudolf Ankersmit's Postmodernist Historical Concept

Yu.A. Martynova*, D.E. Martynov ${ }^{* *}$

Kazan Federal University, Kazan, 420008 Russia

E-mail: "juliemartynova82@gmail.com, ${ }^{* *}$ dmitrymartynov80@mail.ru

Received March 15, 2021

\begin{abstract}
This paper reflects on the modern historiographical situation of perceiving comprehensive historical theories as an obstacle to highly specialized research. On the philosophical level, priority has been given to structuralism and language philosophy, thereby resulting in almost unlimited supremacy of the hermeneutic approach in culture, i.e., in the prevalence of textocentrism. The Dutch philosopher Rudolf Frank Ankersmit argues that postmodernism is both a theory of history and a "theory for history." According to him, historicism is a theory of "historical forms". Thus, the morphology of culture is directly related to historicism. The transformation of historical forms occurs in conditions when the distinction between the text and reality (represented in the text) is erased, and the reality becomes "superfluous" in the context of the overproduction of meanings and interpretations. Therefore, representation ousts the reality. The New Historicism movement emerged in the United States during the second half of the 1980s as a response of literary criticism to the "challenges" of cultural materialism, feminism, or social history. The historical context is considered by the representatives of the New Historiography project as a system of culture, i.e., social institutions and practices (including political ones) are interpreted as functions of this system, and not vice versa.
\end{abstract}

Keywords: historicism, "New Historicism", postmodernism, historical criticism, metanarrative, R. Ankersmit, S. Greenblatt, G. Veeser 


\section{References}

1. Kalimonov I.K. Osnovy nauchnykh issledovanii (zarubezhnaya istoriya) [Basics of Scientific Research (Foreign History)]. Kazan, Kazan. Gos. Univ., 2006. 276 p. (In Russian)

2. West D. Kontinental'naya filosofiya. Vvedenie [Continental Philosophy. An Introduction]. Moscow, Izd. Dom "Delo" RANKhiGS, 2015. 448 p. (In Russian)

3. Rutkevich A.M. Historicism and its critics. Voprosy Filosofii, 2018, no. 12, pp. 24-36. doi: $10.31857 / \mathrm{S} 004287440002580-3$.

4. Ricoeur P. Konflikt interpretatsii: Ocherki o germenevtike [The Conflict of Interpretations: Essays in Hermeneutics]. Moscow, Akad. Proekt, 2008. 695 p. (In Russian)

5. Mandelbaum M. History, Man, and Reason: A Study in Nineteenth-Century Thought. Baltimore, London, Johns Hopkins Univ. Press, 1971. 553 p.

6. Vainshtein O.L. Leopold von Ranke and modern bourgeois historiography. In: Kritika noveishei burzhuaznoi istoriografii [Criticism of Modern Bourgeois Historiography]. Leningrad, Izd. Akad. Nauk SSSR, 1961, pp. 113-149. Trudy Leningradskogo Otdeleniya Instituta Istorii, no. 3. (In Russian)

7. Jameson F. Postmodernism, or, the cultural logic of late capitalism. New Left Review, 1984, no. 146, pp. 59-92.

8. The New Historicism. Aram Veeser H. (Ed.). London, Routledge, 2016. 336 p.

9. Hamilton P. Historicism. London, New York, Routledge, 2003. 211 p.

10. The Limits of Literary Historicism. Dunn A., Haddox T.F. (Eds.). Knoxville, The Univ. of Tenn. Press, 2011. XXV, $180 \mathrm{p}$.

11. Anisimova A.E. "Novyi istorizm": Naukovedcheskii analiz ["New Historicism": Analysis in a Researchon-Research Perspective]. Moscow, INION Ross. Akad. Nauk, 2010. 154 p. (In Russian)

12. Khlebnikov G.V. Book review: 2010.03.020. Anisimova A.E. "New Historicism". Analysis in a Research-on-Research Perspective. RAN INION, Tsentr Nauchn.-Inform. Issled. Nauke, Obraz. Tekhnol. Ed. by Rakitov A.I. Moscow, 2010. 154 p. Sotsial'nye i Gumanitarnye Nauki. Otechestvennaya i Zarubezhnaya Literatura. Seriya 3: Filosofiya, 2010, no. 3, pp. 133-141. (In Russian)

13. Schmidt S.O. "Fenomen Fomenko" v kontekste izucheniya sovremennogo obshchestvennogo istoricheskogo soznaniya ["The Phenomenon of Fomenko" in the Context of the Study of Modern Public Historical Consciousness]. Moscow, Nauka, 2005. 73 p. (In Russian)

/ Для цитирования: Мартынова Ю.А., Мартынов Д.Е. «Новый историзм» и постмодернистская концепция Рудольфа Анкерсмита // Учен. зап. Казан. ун-та. Сер. Гуманит. науки. - 2021. - Т. 163, кн. 3. - С. 21-30. - doi: 10.26907/2541-7738.2021.3.21-30.

For citation: Martynova Yu.A., Martynov D.E. "New Historicism” and Rudolf Ankersmit's postmodernist historical concept. Uchenye Zapiski Kazanskogo Universiteta. Seriya Gumanitarnye Nauki, 2021, vol. 163, no. 3, pp. 21-30. doi: 10.26907/2541-7738.2021.3.21-30. (In Russian) 